\title{
Preoperative risk factors for postoperative intra-abdominal infectious complication after gastrectomy for gastric cancer using a Japanese web-based nationwide database
}

\author{
Keiichi Fujiya ${ }^{1} \cdot$ Hiraku Kumamaru ${ }^{2} \cdot$ Yoshiyuki Fujiwara $^{3} \cdot$ Hiroaki Miyata $^{2} \cdot$ Akira Tsuburaya $^{4} \cdot$ Yasuhiro Kodera $^{5}$. \\ Yuko Kitagawa $^{6} \cdot$ Hiroyuki Konno $^{7} \cdot$ Masanori Terashima $^{1}$ (i)
}

Received: 22 March 2020 / Accepted: 4 May 2020 / Published online: 21 May 2020

(c) The International Gastric Cancer Association and The Japanese Gastric Cancer Association 2020

\begin{abstract}
Background Postoperative intra-abdominal infectious complication (PIIC) after gastrectomy for gastric cancer worsens inhospital death or long-term survival. However, the methodology for PIIC preoperative risk assessment remains unestablished. We aimed to develop a preoperative risk model for postgastrectomy PIIC.

Methods We collected 183,936 patients' data on distal or total gastrectomy performed in 2013-2016 for gastric cancer from the Japanese National Clinical Database and divided into development (2013-2015; $n=140,558)$ and validation (2016; $n=43,378$ ) cohort. The primary outcome was the incidence of PIIC. The risk model for PIIC was developed using 18 preoperative factors: age, sex, body mass index, activities of daily living, 12 comorbidity types, gastric cancer stage, and surgical procedure in the development cohort. Secondarily, we developed another model based on the new scoring system for clinical use using selected factors.

Results The overall incidence of PIIC was $4.7 \%$, including $2.6 \%, 1.7 \%$, and $1.3 \%$ in anastomotic leakage, pancreatic fistula, and intra-abdominal abscess, respectively. Among the 18 preoperative factors, male [odds ratio, (OR) 1.92], obesity (OR, 1.52-1.96), peripheral vascular disease (OR, 1.55), steroid use (OR, 1.83), and total gastrectomy (OR, 1.89) strongly correlated with PIIC incidence. The entire model using the 18 factors had good discrimination and calibration in the validation cohort. We selected eight relevant factors to create a simple scoring system, using which we categorized the patients into three risk groups, which showed good calibration.

Conclusion Using nationwide clinical practice data, we created a preoperative risk model for postgastrectomy PIIC for gastric cancer.
\end{abstract}

Keywords Anastomotic leakage $\cdot$ Gastrectomy $\cdot$ National clinical database $\cdot$ Pancreatic fistula $\cdot$ Risk model

Electronic supplementary material The online version of this article (https://doi.org/10.1007/s10120-020-01083-3) contains supplementary material, which is available to authorized users.

Masanori Terashima

m.terashima@scchr.jp

1 Division of Gastric Surgery, Shizuoka Cancer Center, 1007 Shimonagakubo, Nagaizumi-cho, Sunto-gun,

Shizuoka 411-8777, Japan

2 Department of Healthcare Quality Assessment, Tokyo Graduate School of Medicine, The University of Tokyo, Tokyo, Japan

3 Division of Surgical Oncology, Department of Surgery, School of Medicine, Faculty of Medicine, Tottori University, Yonago, Japan
4 Department of Surgery, Ozawa Hospital, Kanagawa, Japan

5 Department of Gastroenterological Surgery, Nagoya University Graduate School of Medicine, Nagoya, Japan

6 The Japanese Society of Gastroenterological Surgery, Tokyo, Japan

7 Database Committee, The Japanese Society of Gastroenterological, Surgery, Tokyo, Japan 


\section{Introduction}

Gastric cancer is the third leading cause of cancer-related death worldwide [1]. Nevertheless, gastrectomy provides a considerable benefit on the survival of patients with gastric cancer and plays an important role in treatment. Gastric cancer incidence is high in East Asia; annually, around 52,000 patients undergo gastrectomy for gastric cancer treatment in Japan according to the Japanese National Clinical Database (NCD) [2, 3]. Abundant gastrectomies contribute to standardizing the surgical technique and perioperative management, leading to a low mortality of $1.1-2.3 \%$. However, the morbidity rate remains high, accounting for $14.2 \%$ in distal gastrectomy and $21.5 \%$ in total gastrectomy $[2,3]$. Hence, the morbidity rate should be reduced. Among the postgastrectomy complications, anastomotic leakage, intra-abdominal abscess, and pancreatic fistula are defined as postoperative intra-abdominal infectious complications (PIICs), and the incidences of PIIC are reportedly 3.3-10.6\% [4, 5]. PIIC not only causes death or prolongs hospital stays but also worsens long-term survival [6]. This finding has been verified by many studies worldwide [7, 8]. Therefore, surgeons need to particularly pay attention to prevent the PIIC after gastrectomy.

Adequate preoperative evaluation on the risk assessment of complications is essential to decrease morbidity. Thus, it is known that many patient characteristics, such as age, comorbidity, and nutritional status are associated with mortality or morbidity [9-11]. A single factor is insufficient on risk evaluation; therefore, integral assessment tools including patient factors and intraoperative information, such as mE-PASS or POSSUM, had been devised $[12,13]$. However, these indices have limitations. The mE-PASS poorly evaluates the patient's general condition because only three comorbidities and no already well-known risk factors, such as sex and obesity, were included. POSSUM does not include comorbidities and cannot be assessed preoperatively because of the inclusion of intraoperative findings. Furthermore, the endpoints of these indices are mortality and overall morbidity. Therefore, their validity to assess risk for PIIC is unclear.

NCD is a major platform for the nationwide web-based surgical data entry system in Japan. The Japanese Society of Gastroenterological Surgery (JSGS) registry started to collect data in 2011 and has accumulated over 1.2 million gastroenterological surgery records from over 5000 hospitals throughout Japan. The endpoints of previous research in gastric cancer using the NCD were mainly mortality or overall morbidity, and PIIC was not yet recognized [2, 3, 14-21].

Therefore, this study aimed to establish a clinically available preoperative risk model for postgastrectomy
PIIC for patients with gastric cancer. Here we employed the NCD system.

\section{Methods}

\section{Data source}

We used data from the JSGS registry. The NCD runs and maintains the database. All data variables, which were collected via a web-based platform, and their definitions are accessible on the NCD website (https://www.ncd.or.jp/, in Japanese). Considering that the registered data are used for board certification by JSGS and also by Japan Surgical Society, almost all major surgical procedures performed in Japan are expected to be recorded in this national database $[22,23]$. The database committee conducts data verification through sight visit audits at randomly selected institutions [24].

The Ethics Committee of The Japanese Gastric Cancer Association (JGCA) approved this study. All patients were informed about the JSGS registry by the hospitals.

\section{Study population}

Figure 1 displays the study flow chart. Between January 2013 and December 2016, the NCD registered 198,934 patients who underwent distal or total gastrectomy for gastric cancer. Among these patients, 277 with missing data on age, 24 with missing body height data, 13,409 with metastatic gastric cancer, and 1288 who underwent emergent surgery were excluded. A total of 183,936 patients were finally included. Then, we divided them into development cohort (registered between 2013 and 2015, $n=140,558$ ) and validation cohort (registered in 2016, $n=43,378$ ).

\section{Endpoint}

The incidence of PIIC was the primary endpoint of this study. Any morbidity that developed within 30 postoperative days indicated a postoperative complication. PIIC includes anastomotic leakage, intra-abdominal abscess, and pancreatic fistula. Pancreatic fistula was evaluated by the ISGPF criteria, and grade $\mathrm{B}$ or $\mathrm{C}$ was defined as pancreatic fistula [25].

\section{Patient characteristics and predictors}

Based on the potential patient data, tumor and surgical characteristics collected in the NCD-JSGS registry, the following 18 preoperative factors were selected by the research-promoting committee in JGCA as clinically important potential predictors of the outcome: age; sex; body mass index 
Fig. 1 Flow chart of the study population

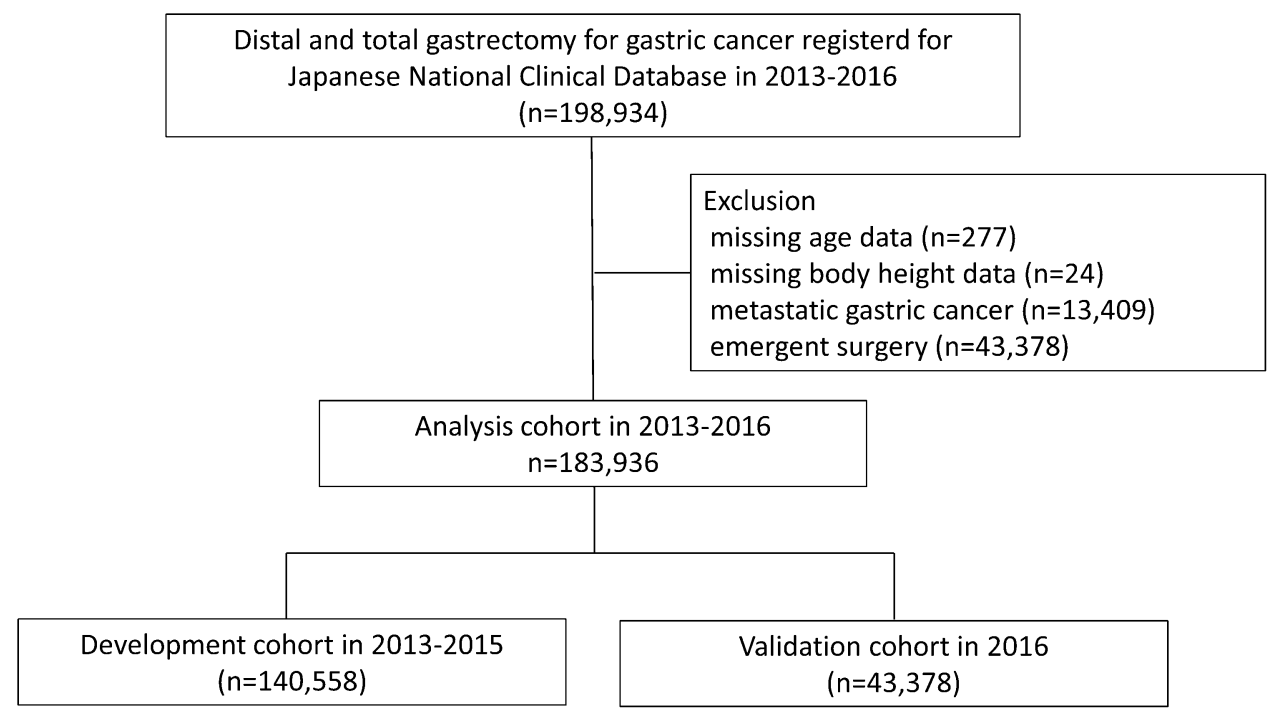

(BMI); activities of daily living (ADL); 12 comorbidity type such as diabetes mellitus, chronic obstructive pulmonary disease (COPD), hypertension, congestive heart failure, coronary artery disease, peripheral arterial disease (PAD), cerebral vascular disease, steroid use, anticoagulant therapy, chronic kidney disease, hemodialysis, and low albumin; surgical TNM cancer stage; and surgical procedure (total or distal gastrectomy). Myocardial infarction, angina, and coronary stent placement defined coronary artery diseases. Meanwhile, a less than $50 \mathrm{~mL} / \mathrm{min}$ in creatinine clearance indicated chronic kidney disease. Most factors were preoperatively obtained, but the preoperative clinical cancer stage was substituted with surgical stage according to the intraoperative findings because no data were available on the clinical stage.

\section{Statistical analysis}

Using logistic regression, we constructed a multivariable risk model based on the development cohort with the 18 abovementioned explanatory variables to predict the occurrence of PIIC after gastrectomy in a primary analysis. The accuracy of the prediction was then tested in the validation cohort by using the c-statistics for discrimination and by calibration plot. Furthermore, we fitted another model that could be easily used in clinical practice, with a fewer number of variables in a secondary analysis. To create a parsimonious model with a reduced number of variables, we used the least absolute shrinkage and selection operator (LASSO) regression method. We chose the shrinkage parameter to eventually reduce the number of variables to 12 . We scored the variables according to the odds ratios estimated in the model, excluded four variables, and finally narrowed to eight variables. The cohort was stratified into three risk groups for PIIC according to the score of the eight variables.
Furthermore, we verified whether the groups were distinct in terms of the risks for PIIC in the validation cohort.

\section{Results}

\section{Risk profile of the study population}

Patients' demographic data and cancer factors are summarized in Table 1. The population in the development cohort had a mean age of 70.5 years, and two-thirds of patients were males. Patients who were obese with a BMI of over $25 \mathrm{~kg} / \mathrm{m}^{2}$ were around $20 \%$ of the development cohort. Major comorbidities were hypertension, followed by chronic kidney diseases, low serum albumin, and diabetes mellitus. Almost half of the patients showed stage I. Moreover, around 70\% and $30 \%$ of patients underwent distal gastrectomy and total gastrectomy, respectively. Each prevalence of these descriptive data was similar between the development and validation cohorts.

\section{Morbidity}

All complications with grade II or higher in Clavien-Dindo classification occurred in $15.6 \%$ of the whole study population $[26,27]$. The overall incidence of PIIC was $4.7 \%$ (Supplementary Table 1). In particular, $2.6 \%$ had anastomotic leakage, $1.7 \%$ had a pancreatic fistula, and $1.3 \%$ had intraabdominal abscess.

\section{Model results}

The multivariate logistic model for PIIC in the development cohort is presented in Table 2. Age, sex, BMI, ADL, 12 types of comorbidities, gastric cancer stage, and surgical 
Table 1 Key descriptive data in the development and validation cohorts

\begin{tabular}{|c|c|c|c|c|}
\hline & \multirow{2}{*}{\multicolumn{2}{|c|}{$\begin{array}{l}\text { Development } \\
\text { cohort } \\
(n=140,558) \\
{[\%]}\end{array}$}} & \multirow{2}{*}{\multicolumn{2}{|c|}{$\begin{array}{l}\begin{array}{l}\text { Validation } \\
\text { cohort }\end{array} \\
(n=43,378) \\
{[\%]}\end{array}$}} \\
\hline & & & & \\
\hline \multicolumn{5}{|l|}{ Age } \\
\hline$<65$ & 38,882 & {$[27.7]$} & 10,574 & [24.4] \\
\hline $65-74$ & 50,277 & {$[35.8]$} & 16,152 & [37.2] \\
\hline $75-84$ & 42,702 & {$[30.4]$} & 13,608 & [31.4] \\
\hline$>84$ & 8697 & {$[6.2]$} & 3044 & [7.0] \\
\hline \multicolumn{5}{|l|}{ Sex } \\
\hline Female & 43,788 & [31.2] & 13,635 & [31.4] \\
\hline Male & 96,770 & {$[68.8]$} & 29,743 & [68.6] \\
\hline \multicolumn{5}{|l|}{ Body mass index (BMI) } \\
\hline$<18.5$ & 18,181 & [12.9] & 5447 & [12.6] \\
\hline $18.5-25$ & 95,138 & {$[67.7]$} & 29,197 & [67.3] \\
\hline $25-30$ & 24,139 & {$[17.2]$} & 7685 & [17.7] \\
\hline$\geq 30$ & 3082 & [2.2] & 1047 & [2.4] \\
\hline Missing & 18 & {$[0]$} & 2 & {$[0]$} \\
\hline \multicolumn{5}{|l|}{ Activities of daily living (ADL) } \\
\hline Any assistance & 6059 & [4.3] & 1693 & [3.9] \\
\hline \multicolumn{5}{|l|}{ Comorbidity } \\
\hline Diabetes mellitus & 23,104 & [16.4] & 7569 & [17.4] \\
\hline $\begin{array}{l}\text { Chronic obstructive pulmonary } \\
\text { disease }\end{array}$ & 6647 & [4.7] & 2335 & {$[5.4]$} \\
\hline Hypertension & 54,707 & [38.9] & 17,927 & [41.3] \\
\hline Congestive heart failure & 951 & {$[0.7]$} & 297 & {$[0.7]$} \\
\hline Coronary artery disease & 5267 & [3.7] & 1679 & [3.9] \\
\hline Peripheral arterial disease & 1097 & {$[0.8]$} & 300 & {$[0.7]$} \\
\hline Cerebral vascular disease & 2550 & [1.8] & 732 & [1.7] \\
\hline Steroid use & 1301 & [0.9] & 429 & [1.0] \\
\hline Anticoagulant therapy & 5546 & [3.9] & 1862 & [4.3] \\
\hline Chronic kidney disease & 30,670 & [21.8] & 9675 & [22.3] \\
\hline Hemodialysis & 1037 & {$[0.7]$} & 311 & [0.7] \\
\hline Serum albumin $\leq 3.5 \mathrm{~g} / \mathrm{dL}$ & 25,792 & {$[18.3]$} & 8410 & [19.4] \\
\hline \multicolumn{5}{|l|}{ Gastric cancer stage } \\
\hline I & 79,186 & {$[56.3]$} & 24,218 & {$[55.8]$} \\
\hline II/III & 61,259 & [43.6] & 19,160 & [44.2] \\
\hline Missing & 113 & {$[0.1]$} & 0 & {$[0]$} \\
\hline \multicolumn{5}{|l|}{ Surgical procedure } \\
\hline Distal gastrectomy & 98,991 & [70.4] & 31,440 & [72.5] \\
\hline Total gastrectomy & 41,567 & [29.6] & 11,938 & [27.5] \\
\hline
\end{tabular}

procedure were associated with morbidity incidence. Among them, male, obesity, peripheral vascular disease, steroid use, and total gastrectomy were strong factors. The predicted morbidity was based on the following logistic regression equation:

Predicted morbidity $=\mathrm{e}(-4.272+\Sigma \beta i) /\{1+\mathrm{e}(-4.272+\Sigma \beta i)\}$ where $\beta i$ is the coefficient of the variable factors (Table 2).

\section{Model performance}

To evaluate the performance of this model, we performed calibration and discrimination by using the validation cohort. According to the calibration plot, the predicted probability and actual incidence fairly correlated (Fig. 2a). In addition, the area under the ROC curve (AUC) was 0.666 (95\% confidence interval [CI], 0.660-0.672) (Fig. 2b).

\section{Simple prediction for intra-abdominal Infectious complication after Gastrectomy for gastric caNcer (SIGN score)}

A reduced-risk model with simple and broad practicality for PIIC was constructed in the development cohort by using the LASSO regression method. Table 3 shows the estimates from the LASSO multivariable logistic model, which reduced the number of risk factors from 18 to 12 . This reduced-risk model was expressed through the following equation:

Predicted morbidity $=\mathrm{e}(-3.799+\Sigma \beta i) /\{1+\mathrm{e}(-3.799+\Sigma \beta i)\}$

These factors were scored to predict morbidity according to the coefficient $(0.03<\beta \leq 0.09,1$ point; $0.09<\beta \leq 0.19$, 2 points; $0.19<\beta \leq 0.29,4$ points; $0.29<\beta \leq 0.39,6$ points; $0.39<\beta \leq 0.49,8$ points; and $0.49<\beta \leq 0.59,10$ points). Four factors, namely, age, diabetes mellitus, COPD, and anticoagulant therapy, with a coefficient of less than 0.03 were deleted, and the scoring system eventually included eight factors and was named SIGN score. Male, obese, advanced cancer stage, and total gastrectomy strongly affected morbidity incidence. Patients were stratified into three risk groups (low-risk group, 0-7; middle-risk group, 8-15; and high-risk group, 16-31) according to the SIGN score. The predicted probabilities for PIIC in the low-, middle-, and high-risk groups were $1.8 \%, 4.1 \%$, and $7.8 \%$, respectively, using the development cohort. The prediction had good calibration against the observed incidence in the validation cohort (Fig. 3). The low-, middle-, and highrisk groups of the validation cohort had 9,917; 22,120; and 11,341 patients, respectively.

\section{Discussion}

In this study, a satisfactory risk model for PIIC was constructed using a large-scale database in clinical practice. As aging progresses worldwide, surgical high-risk patients also increase in number, and the importance of risk assessment further grows [28]. PIICs can be fatal, especially in 
Table 2 Risk factors associated with postoperative intra-abdominal infectious complications in the development cohort

\begin{tabular}{|c|c|c|c|c|c|}
\hline & \multirow[b]{2}{*}{$\beta$ coefficient } & \multirow[b]{2}{*}{ Odds ratio } & \multicolumn{2}{|l|}{$95 \% \mathrm{CI}$} & \multirow[b]{2}{*}{$p$ value } \\
\hline & & & Lower & Higher & \\
\hline Intercept & -4.272 & & & & \\
\hline \multicolumn{6}{|l|}{ Age } \\
\hline$<65$ & Reference & & & & \\
\hline $65-74$ & 0.136 & 1.15 & 1.07 & 1.23 & $<.001$ \\
\hline $75-84$ & 0.146 & 1.16 & 1.07 & 1.25 & $<.001$ \\
\hline$>84$ & -0.107 & 0.90 & 0.78 & 1.03 & 0.13 \\
\hline \multicolumn{6}{|l|}{ Sex } \\
\hline Female & Reference & & & & \\
\hline Male & 0.652 & 1.92 & 1.80 & 2.05 & $<.001$ \\
\hline \multicolumn{6}{|l|}{ Body mass index (BMI) } \\
\hline$<18.5$ & -0.231 & 0.79 & 0.73 & 0.87 & $<.001$ \\
\hline $18.5-25$ & Reference & & & & \\
\hline $25-30$ & 0.420 & 1.52 & 1.43 & 1.62 & $<.001$ \\
\hline$\geq 30$ & 0.674 & 1.96 & 1.71 & 2.26 & $<.001$ \\
\hline \multicolumn{6}{|l|}{ Activities of daily living (ADL) } \\
\hline Any assistance & 0.210 & 1.23 & 1.10 & 1.39 & $<.001$ \\
\hline \multicolumn{6}{|l|}{ Comorbidity } \\
\hline Diabetes mellitus & 0.102 & 1.11 & 1.04 & 1.18 & 0.002 \\
\hline Chronic obstructive pulmonary disease & 0.246 & 1.28 & 1.16 & 1.42 & $<.001$ \\
\hline Hypertension & 0.207 & 1.23 & 1.17 & 1.30 & $<.001$ \\
\hline Congestive heart failure & -0.200 & 0.82 & 0.61 & 1.10 & 0.19 \\
\hline Coronary artery disease & 0.188 & 1.21 & 1.08 & 1.35 & 0.001 \\
\hline Peripheral arterial disease & 0.440 & 1.55 & 1.26 & 1.92 & $<.001$ \\
\hline Cerebral vascular disease & 0.144 & 1.16 & 0.98 & 1.36 & 0.08 \\
\hline Steroid use & 0.605 & 1.83 & 1.49 & 2.25 & $<.001$ \\
\hline Anticoagulant therapy & 0.153 & 1.17 & 1.04 & 1.31 & 0.01 \\
\hline Chronic kidney disease & -0.003 & 1.00 & 0.93 & 1.07 & 0.93 \\
\hline Hemodialysis & 0.173 & 1.19 & 0.92 & 1.54 & 0.20 \\
\hline Serum albumin $\leq 3.5 \mathrm{~g} / \mathrm{dL}$ & 0.090 & 1.10 & 1.02 & 1.17 & 0.01 \\
\hline \multicolumn{6}{|l|}{ Gastric cancer stage } \\
\hline I & Reference & & & & \\
\hline II/III & 0.327 & 1.39 & 1.32 & 1.46 & $<.001$ \\
\hline \multicolumn{6}{|l|}{ Surgical procedure } \\
\hline Distal gastrectomy & Reference & & & & \\
\hline Total gastrectomy & 0.638 & 1.89 & 1.80 & 1.99 & $<.001$ \\
\hline
\end{tabular}

fragile patients. Super-elderly individuals or those with multiple severe comorbidities were conventionally considered frail for surgery. Nonetheless, they can be evaluated through this risk model and may undergo limited gastrectomy or lymphadenectomy.

Risk stratification models for operative morbidities after gastrectomy have been constructed individually in distal and total gastrectomies by using the data from NCD [2, 3]. However, integral outcomes, such as PIIC, have not been investigated. To unify in a single model, we did not separate the distal and total gastrectomies. Although total gastrectomy was the strongest factor, the unified model remained robust.
Among the postgastrectomy complications, PIIC is a critical complication depending on surgical technique and is related to in-hospital death, long hospital stays or worsened long-term survival $[29,30]$. The major reasons of death within 90 days after gastrectomy were cardiac events followed by PIIC, pneumonia, and events in the central nervous system in the NCD [15]. Intra-abdominal abscess mainly includes anastomotic leakage and pancreatic fistula; thus, we encompassed these three complications. In our study, the overall incidence of anastomotic leakage was $2.6 \%$, which was the highest among the three complications. High leakage incidence may be caused by total gastrectomy, accounting for $30 \%$. Anastomotic leakages in distal and 
Fig. 2 Calibration and discrimination for the risk model. a Calibration plot between the development and validation cohorts. b Discrimination plot between the development and validation cohorts. The AUC was 0.666

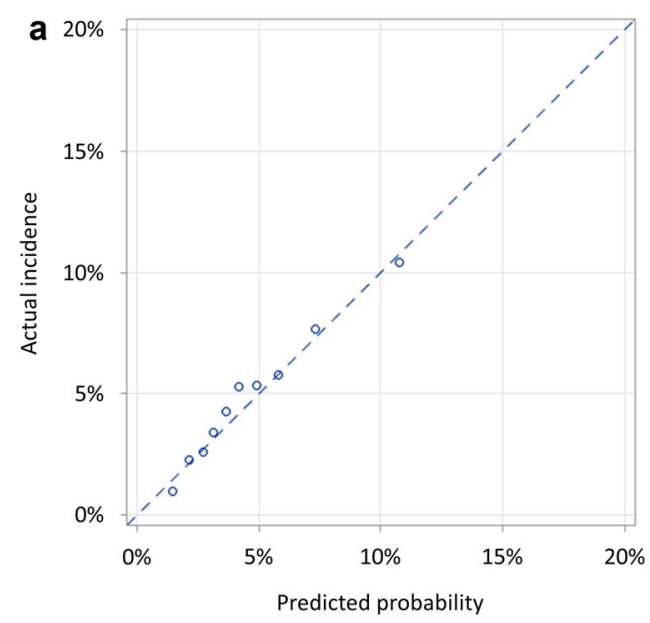

Table 3 Reduced-risk model for the postoperative intra-abdominal infectious complications in the development cohort

\begin{tabular}{|c|c|c|}
\hline & $\beta$ coefficient & Score $(0-31)$ \\
\hline Intercept & -3.799 & \\
\hline \multicolumn{3}{|l|}{ Age } \\
\hline$<65$ & Reference & \\
\hline$\geq 65$ & 0 & 0 \\
\hline \multicolumn{3}{|l|}{ Sex } \\
\hline Female & Reference & \\
\hline Male & 0.486 & 8 \\
\hline \multicolumn{3}{|l|}{ Body mass index (BMI) } \\
\hline$<25$ & Reference & \\
\hline $25-30$ & 0.255 & 4 \\
\hline$\geq 30$ & 0.248 & 4 \\
\hline \multicolumn{3}{|l|}{ Comorbidity } \\
\hline Diabetes mellitus & 0.028 & 0 \\
\hline $\begin{array}{l}\text { Chronic obstructive pulmonary } \\
\text { disease }\end{array}$ & 0.025 & 0 \\
\hline Hypertension & 0.157 & 2 \\
\hline Coronary artery disease & 0.042 & 1 \\
\hline Peripheral arterial disease & 0.066 & 1 \\
\hline Steroid use & 0.051 & 1 \\
\hline Anticoagulant therapy & 0.012 & 0 \\
\hline \multicolumn{3}{|l|}{ Gastric cancer stage } \\
\hline I & Reference & \\
\hline II/III & 0.199 & 4 \\
\hline \multicolumn{3}{|l|}{ Surgical procedure } \\
\hline Distal gastrectomy & Reference & \\
\hline Total gastrectomy & 0.528 & 10 \\
\hline
\end{tabular}

total gastrectomies from the NCD in 2011-2012 were 2.1\% and $4.5 \%$, respectively $[2,3]$. According to both retrospective and prospective cohort studies using NCD, pancreatic fistula frequently occurs in patients undergoing laparoscopic distal gastrectomy than open distal gastrectomy $[17,18]$.

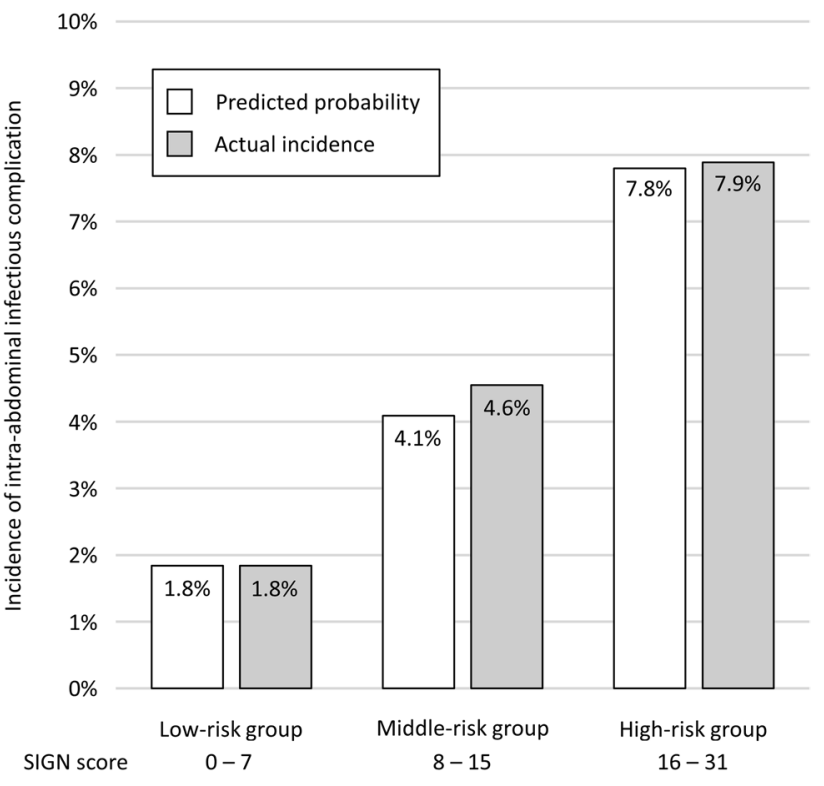

Fig. 3 Comparison between the development and validation cohorts for the incidence of postoperative intra-abdominal infectious complication according to three risk groups. Left white bar indicates the predicted probability from the reduced-risk model in the development cohort. Right gray bar indicates the actual incidence in the validation cohort

Therefore, surgeons need to consider high-risk patients based on our model when performing laparoscopic distal gastrectomy.

Various types of comorbidity were associated with postoperative complications [31,32]. This study revealed that preoperative steroid use, PAD, COPD, and hypertension strongly correlated with PIIC. Chronic steroid use increases infection risks or interferes with healing, and it is linked to anastomotic leakage [33]. Arteriosclerotic diseases such as hypertension or PAD causes negative effects on microvascular and oxygen perfusion and inhibit anastomotic healing $[34,35]$. Low pulmonary function also leads to tissue 
hypoxia and anastomotic leakage [36]. Preoperative inflammation markers were not included in our model, because white blood cell and C-reactive protein with mild to moderate increase were not a major risk for abdominal abscess and pancreas fistula in previous NCD studies [2, 3].

Reduced-risk model can be available in general practice. However, despite its rigorous nature, considerably many factors or complicated calculations may disturb its routine use. Therefore, we narrowed 18 factors in the entire model to eight factors according to the prevalence and $\beta$ coefficient to create a new scoring system, named as the SIGN score. It could stratify patients into three risk categories. Despite having high prevalence, factors with low $\beta$ coefficient, such as diabetes mellitus, were excluded in this scoring system. Meanwhile, age was not an independent factor of PIIC in the reduced-risk model, and it supports the results of previous studies to indicate the feasibility and safety of gastrectomy in advanced age [37, 38]. Hence, limited surgery may be dispensable for healthy elderly patients.

This study has several limitations. NCD, which was used in this study, lacks detailed preoperative tumor information such as tumor location, size, clinical cancer stage, and planning of the surgical procedure and the extent of lymphadenectomy. Preoperative cancer stage is unknown, however, clinical stage includes a surgical stage in the 8th edition of the TNM classification [39]. Second, the severity of anastomotic leakage and intra-abdominal abscess is unknown. Third, neoadjuvant chemotherapy for gastric cancer is not a standard treatment in Japan. Only 3.4\% of the study cohort received neoadjuvant chemotherapy. Therefore, we did not include it as a risk factor in this model, although neoadjuvant chemotherapy increases morbidity [40]. The strength of this risk model is that relevant risk factors for a wide range of comorbidities were identified and quantified using the nationally representative data. Some of the comorbidities could be controlled by preoperative intervention. For example, a preoperative physical exercise program could be implemented to control body weight and to build muscle, and preoperative respiratory rehabilitation could be proposed for patients with COPD [41]. Future challenges include evaluation of the efficacy of such preoperative intervention in reducing the incidence of PIIC in patients at high risk in this model.

\section{Conclusion}

A preoperative entire risk model for PIIC that occurs after gastrectomy for gastric cancer was developed on the basis of real-world nationwide clinical practice data. This led to the establishment of a new, simple scoring system that is more practical for clinical use. Other known risk factors had been included in the original risk analyses, and the identification of the most relevant eight factors is new to the literature. Thus, we believe that the current series of analyses, starting from the entire risk models including a wide range of comorbidities, was a valuable approach in establishing a novel tool for preoperative risk evaluation.

Acknowledgements The authors would like to thank all data managers and hospitals for their great efforts who participated in this NCD project.

Funding This work was supported by a grant from the Japanese Gastric Cancer Association.

\section{Compliance with ethical standards}

Conflict of interest Hiraku Kumamaru and Hiroaki Miyata are affiliated with the department of Healthcare Quality Assessment at the University of Tokyo Graduate School of Medicine. The department is a social collaboration department supported by National Clinical Database, Johnson \& Johnson K.K., and Nipro Corporation. Dr. Kodera reports grants from Taiho Pharma, grants from Chugai Pharma, grants from Takeda, grants from MSD, grants from NIhon Kayaku, grants from Yakult, grants from Lilly Japan, grants from Ono Pharma, grants from Kaken Pharma, grants from Covidien, grants from EA Pharma, grants from Novartis, grants from KCI, grants from Maruho, grants from Daiichi Sankyo, grants from Otsuka, grants from Tsumura, grants from Sawai, personal fees from Taiho Pharma, personal fees from Chugai Pharma, personal fees from Lilly Japan, personal fees from Johnson \& Johnson, personal fees from Takeda, personal fees from Yakult, personal fees from Otsuka, personal fees from Ono Pharma, personal fees from Covidien, personal fees from MSD, grants from Bristol, grants from Sanofi, outside the submitted work. Dr. Terashima reports personal fees from Taiho, personal fees from Chugai, personal fees from Ono, personal fees from BMS, personal fees from Yakult, personal fees from Takeda, personal fees from Eli Lilly, personal fees from Pfizer, personal fees from Daiichi Sankyo, outside the submitted work. Drs. Fujiya, Fujiwara, Tsuburaya, Kitagawa and Konno have nothing to disclose.

Ethical approval This study conforms to the ethical guidelines of the Helsinki Declaration. The use of data from the registry was approved by The Japanese Society of Gastroenterological Surgery committee. All patients were informed about the JSGS registry by the hospitals.

\section{References}

1. Bray F, Ferlay J, Soerjomataram I, Siegel RL, Torre LA, Jemal A. Global cancer statistics 2018: GLOBOCAN estimates of incidence and mortality worldwide for 36 cancers in 185 countries. CA Cancer J Clin. 2018;68:394-424.

2. Kunisaki C, Miyata H, Konno H, Saze Z, Hirahara N, Kikuchi $\mathrm{H}$, et al. Modeling preoperative risk factors for potentially lethal morbidities using a nationwide Japanese web-based database of patients undergoing distal gastrectomy for gastric cancer. Gastric Cancer. 2017;20:496-507.

3. Kikuchi H, Miyata H, Konno H, Kamiya K, Tomotaki A, Gotoh $\mathrm{M}$, et al. Development and external validation of preoperative risk models for operative morbidities after total gastrectomy using a Japanese web-based nationwide registry. Gastric Cancer. 2017;20:987-97. 
4. Tokunaga M, Tanizawa Y, Bando E, Kawamura T, Terashima M. Poor survival rate in patients with postoperative intra-abdominal infectious complications following curative gastrectomy for gastric cancer. Ann Surg Oncol. 2013;20:1575-83.

5. Tokunaga M, Makuuchi R, Miki Y, Tanizawa Y, Bando E, Kawamura $\mathrm{T}$, et al. Late phase II study of robot-assisted gastrectomy with nodal dissection for clinical stage I gastric cancer. Surg Endosc. 2016;30:3362-7.

6. Tokunaga M, Kondo J, Tanizawa Y, Bando E, Kawamura T, Terashima M. Postoperative intra-abdominal complications assessed by the Clavien-Dindo classification following open and laparoscopy-assisted distal gastrectomy for early gastric cancer. J Gastrointest Surg. 2012;16:1854-9.

7. Pucher PH, Aggarwal R, Qurashi M, Darzi A. Meta-analysis of the effect of postoperative in-hospital morbidity on long-term patient survival. Br J Surg. 2014;101:1499-508.

8. Wang S, Xu L, Wang Q, Li J, Bai B, Li Z, et al. Postoperative complications and prognosis after radical gastrectomy for gastric cancer: a systematic review and meta-analysis of observational studies. World J Surg Oncol. 2019;17:52.

9. Jeong SH, Ahn HS, Yoo MW, Cho JJ, Lee HJ, Kim HH, et al. Increased morbidity rates in patients with heart disease or chronic liver disease following radical gastric surgery. J Surg Oncol. 2010;101:200-4.

10. Hayashi T, Yoshikawa T, Aoyama T, Ogata T, Cho H, Tsuburaya A. Severity of complications after gastrectomy in elderly patients with gastric cancer. World J Surg. 2012;36:2139-45.

11. Ryo RS, Kanda M, Ito S, Mochizuki Y, Teramoto H, et al. The controlling nutritional status score serves as a predictor of shortand long-term outcomes for patients with stage 2 or 3 gastric cancer: analysis of a multi-institutional data set. Ann Surg Oncol. 2019;26:456-64.

12. Copeland GP, Jones D, Walters M. POSSUM: a scoring system for surgical audit. Br J Surg. 1991;78:355-60.

13. Haga Y, Wada Y, Takeuchi H, Ikejiri K, Ikenaga M, Kimura O. Evaluation of modified estimation of physiologic ability and surgical stress in gastric carcinoma surgery. Gastric Cancer. 2012;15:7-14.

14. Watanabe M, Miyata $\mathrm{H}$, Gotoh $\mathrm{M}$, Baba H, Kimura W, Tomita N, et al. Total gastrectomy risk model: data from 20,011 Japanese patients in a nationwide internet-based database. Ann Surg. 2014;260:1034-9.

15. Kurita N, Miyata H, Gotoh M, Shimada M, Imura S, Kimura $\mathrm{W}$, et al. Risk model for distal gastrectomy when treating gastric cancer on the basis of data from 33,917 Japanese patients collected using a nationwide web-based data entry system. Ann Surg. 2015;262:295-303.

16. Etoh T, Honda M, Kumamaru H, Miyata H, Yoshida K, Kodera Y, et al. Morbidity and mortality from a propensity score-matched, prospective cohort study of laparoscopic versus open total gastrectomy for gastric cancer: data from a nationwide web-based database. Surg Endosc. 2018;32:2766-73.

17. Yoshida K, Honda M, Kumamaru H, Kodera Y, Kakeji Y, Hiki $\mathrm{N}$, et al. Surgical outcomes of laparoscopic distal gastrectomy compared to open distal gastrectomy: a retrospective cohort study based on a nationwide registry database in Japan. Ann Gastroenterol Surg. 2018;2:55-64.

18. Hiki N, Honda M, Etoh T, Yoshida K, Kodera Y, Kakeji Y, et al. Higher incidence of pancreatic fistula in laparoscopic gastrectomy. Real-world evidence from a nationwide prospective cohort study. Gastric Cancer. 2018;21:162-70.

19. Iwatsuki M, Yamamoto H, Miyata H, Kakeji Y, Yoshida K, Konno $\mathrm{H}$, et al. Effect of hospital and surgeon volume on postoperative outcomes after distal gastrectomy for gastric cancer based on data from 145,523 Japanese patients collected from a nationwide webbased data entry system. Gastric Cancer. 2019;22:190-201.
20. Kodera Y, Yoshida K, Kumamaru H, Kakeji Y, Hiki N, Etoh T, et al. Introducing laparoscopic total gastrectomy for gastric cancer in general practice: a retrospective cohort study based on a nationwide registry database in Japan. Gastric Cancer. 2019;22:202-13.

21. Inokuchi M, Kumamaru H, Nakagawa M, Miyata H, Kakeji Y, Seto Y, et al. Feasibility of laparoscopic gastrectomy for patients with poor physical status: a retrospective cohort study based on a nationwide registry database in Japan. Gastric Cancer. 2020;23:310-8.

22. Otsubo T, Kobayashi S, Sano K, Misawa T, Ota T, Katagiri S, et al. Safety-related outcomes of the Japanese Society of HepatoBiliary-Pancreatic Surgery board certification system for expert surgeons. J Hepatobiliary Pancreat Sci. 2017;24:252-61.

23. Konno H, Kamiya K, Kikuchi H, Miyata H, Hirahara N, Gotoh M, et al. Association between the participation of board-certified surgeons in gastroenterological surgery and operative mortality after eight gastroenterological procedures. Surg Today. 2017;47:611-8.

24. Kimura W, Miyata H, Gotoh M, Hirai I, Kenjo A, Kitagawa Y, et al. A pancreaticoduodenectomy risk model derived from 8575 cases from a national single-race population (Japanese) using a web-based data entry system: the 30-day and in-hospital mortality rates for pancreaticoduodenectomy. Ann Surg. 2014;259:773-80.

25. Bassi C, Dervenis C, Butturini G, Fingerhut A, Yeo C, Izbicki J, et al. Postoperative pancreatic fistula: an international study group (ISGPF) definition. Surgery. 2005;138:8-13.

26. Dindo D, Demartines N, Clavien PA. Classification of surgical complications: a new proposal with evaluation in a cohort of 6336 patients and results of a survey. Ann Surg. 2004;240:205-13.

27. Clavien PA, Barkun J, de Oliveira ML, Vauthey JN, Dindo D, Schulick RD, et al. The Clavien-Dindo classification of surgical complications: five-year experience. Ann Surg. 2009;250:187-96.

28. Barnett K, Mercer SW, Norbury M, Watt G, Wyke S, Guthrie B. Epidemiology of multimorbidity and implications for health care, research, and medical education: a cross-sectional study. Lancet. 2012;380:37-433.

29. Tsujimoto H, Ichikura T, Ono S, Sugasawa H, Hiraki S, Sakamoto $\mathrm{N}$, et al. Impact of postoperative infection on long-term survival after potentially curative resection for gastric cancer. Ann Surg Oncol. 2009;16:311-8.

30. Sierzega M, Kolodziejczyk P, Kulig J, Polish Gastric Cancer Study G. Impact of anastomotic leakage on long-term survival after total gastrectomy for carcinoma of the stomach. Br J Surg. 2010;97:1035-42.

31. McCulloch P, Ward J, Tekkis PP, Surgeons Ago, British Oesophago-Gastric Cancer G. Mortality and morbidity in gastrooesophageal cancer surgery initial results of ASCOT multicentre prospective cohort study. BMJ. 2003;327:1192-7.

32. Kim W, Song KY, Lee HJ, Han SU, Hyung WJ, Cho GS. The impact of comorbidity on surgical outcomes in laparoscopyassisted distal gastrectomy: a retrospective analysis of multicenter results. Ann Surg. 2008;248:793-9.

33. Hefler J, Dang J, Modasi A, Switzer N, Birch DW, Karmali S. Effects of chronic corticosteroid and immunosuppressant use in patients undergoing bariatric surgery. Obes Surg. 2019;29:3309-15.

34. Pham TH, Perry KA, Enestvedt CK, Gareau D, Dolan JP, Sheppard BC, et al. Decreased conduit perfusion measured by spectroscopy is associated with anastomotic complications. Ann Thorac Surg. 2011;91:380-5.

35. Goense L, van Rossum PSN, Weijs TJ, van Det MJ, Nieuwenhuijzen GA, Luyer MD, et al. Aortic calcification increases the risk of anastomotic leakage after Ivor-Lewis esophagectomy. Ann Thorac Surg. 2016;102:247-52.

36. Rencuzogullari A, Benlice C, Valente M, Abbas MA, Remzi FH, Gorgun E. Predictors of anastomotic leak in elderly patients after colectomy: nomogram-based assessment from the American 
college of surgeons national surgical quality program proceduretargeted cohort. Dis Colon Rectum. 2017;60:527-36.

37. Kunisaki C, Akiyama H, Nomura M, Matsuda G, Otsuka Y, Ono $\mathrm{HA}$, et al. Comparison of surgical outcomes of gastric cancer in elderly and middle-aged patients. Am J Surg. 2006;191:216-24.

38. Brenkman HJF, Goense L, Brosens L, Haj Mohammad N, Vleggaar F, Ruurda J, et al. A high lymph node yield is associated with prolonged survival in elderly patients undergoing curative gastrectomy for cancer: a Dutch population-based cohort study. Ann Surg Oncol. 2017;24:2213-23.

39. Brierley JD, Gospodarowicz MK, Wittekind C. TNM classification of malignant tumours. 8th ed. New York: Wiley-Blackwell; 2017.

40. Robb WB, Messager M, Goere D, Pichot-Delahaye V, Lefevre JH, Louis D, et al. Predictive factors of postoperative mortality after junctional and gastric adenocarcinoma resection. JAMA Surg. 2013;148:624-31.

41. Miki Y, Makuuchi R, Honda S, Tokunaga M, Tanizawa Y, Bando E, et al. Prospective phase II study evaluating the efficacy of swallow ability screening tests and pneumonia prevention using a team approach for elderly patients with gastric cancer. Gastric Cancer. 2018;21:353-9.

Publisher's Note Springer Nature remains neutral with regard to jurisdictional claims in published maps and institutional affiliations. 